Research article

\title{
From single-use to multi-use: Study of consumers' behavior toward consumption of reusable containers
}

\author{
Myriam Ertz ${ }^{\text {a, }}$, Rong Huang ${ }^{\text {b, } 2}{ }^{\text {, Myung-Soo Jo }}{ }^{\text {c, } 3}$, Fahri Karakas ${ }^{\text {d, }}{ }^{*}$, Emine Sarigöllü ${ }^{c, 4}$ \\ a School of Management Sciences at Université du Québec à Montréal, 315 Sainte-Catherine Street East, Montreal, Quebec, H2X 3X2, Canada \\ b School of International Business Administration, Shanghai University of Finance and Economics, 200433, China

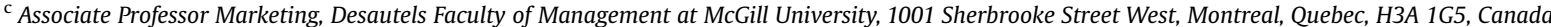 \\ ${ }^{\mathrm{d}}$ Lecturer in Business and Leadership, Norwich Business School, University of East Anglia, Norwich Research Park, Norwich, Norfolk, NR4 7TJ, United \\ Kingdom
}

\section{A R T I C L E I N F O}

\section{Article history:}

Received 28 June 2016

Received in revised form

28 August 2016

Accepted 25 January 2017

Available online 23 February 2017

\section{Keywords:}

Context

Culture

Intentions

Motivation

Reusable container consumption

Theory of planned behavior

\begin{abstract}
A B S T R A C T
This study advances the theory of planned behavior (TPB) to identify the mechanism that underlies the consumption of reusable containers. A questionnaire including context, motivation, subjective norms, attitudes, perceived behavioral control, intentions and behavior items was developed and pre-tested on 180 students in a Canadian and a Chinese university respectively. Subsequently, the questionnaire was implemented in the form of an online survey and 1221 effective responses were collected from Western $(n=549)$ and Asian $(n=672)$ consumers. The findings revealed that the context and motivation variables are important antecedents to several TPB constructs. Context strongly impacts perceived behavioral control and motivations as well as attitudes. Motivation is clearly distinct from intentions and has a significant influence on both attitudes and intentions. In addition to the standard variables of perceived behavioral control, subjective norms and attitudes, motivation does have a significant impact on intentions. Furthermore, there are cultural differences in the way context impacts intentions and behavior in that Asians (Westerners) are influenced by context to increase reusable containers consumption through motivation (attitudes). Attitude is a significantly stronger predictor of intentions for Westerners than Asians.
\end{abstract}

๑) 2017 Elsevier Ltd. All rights reserved.

\section{Introduction}

The management of waste is of increasing importance (Inglezakis and Moustakas, 2013; Wagner et al., 2013). Past research has mostly focused on reduce and recycle, but largely ignored reuse. Reuse refers to any activity that lengthens the life of an item (Allegrini et al., 2015) and is among the most critical strategies for long-term sustainability based on waste reduction (Haws et al., 2013). Reuse is known to be more effective than recycling in waste reduction, resource conservation and sustaining quality of life.

\footnotetext{
* Corresponding author. Tel.: +44 1603597192 .

E-mail addresses: ertz.myriam@courrier.uqam.ca (M. Ertz), email_huangrong@ 163.com (R. Huang), myung-soo.jo@mcgill.ca (M.-S. Jo), f.karakas@uea.ac.uk (F. Karakas), emine.sarigollu@mcgill.ca (E. Sarigöllü).

1 Tel.: +15149873000.

2 Tel.: +862165906919.

3 Tel: +1 5143984780 .

4 Tel.: +1 5143984662 .
}

Despite the critical role of reuse in the optimum use of raw materials, past research has exclusively focused on the external factors influencing reuse, such as political, social, and economic (e.g. Suthar et al., 2016), but ignored the psychological factors on consumers' reuse behavior. Behavioral perspectives on consumer's consumption of reusable containers are sparse, a remarkable oversight given the criticality of reuse (Haws et al., 2013). There is a gap of research on consumer behavior insights and solutions that put consumer reuse at the center of attention. Furthermore, there is a lack of research utilizing behavioral perspectives to understand consumers' consumption of reusable containers. This paper addresses these gaps. We focus on consumer reuse as a key to waste reduction and sustainability; analyzing the role of context, motivation, and culture in how consumers consume reusable containers.

By studying the role of context and motivation variables in relation to reuse behavior, the current research addresses two gaps in the literature. First, it answers previous calls to augment the examination of pro-environmental behavior from an intra-psychic 
viewpoint, with extra-psychic variables, such as context (Steg and Vlek, 2009; Ertz et al., 2016). Second, the long tradition of motivational studies in psychology has produced a rich theoretical corpus about motivation which may be drawn upon to foster proenvironmental behavior such as re-use.

Disposable single-use containers are at the origin of various environmental as well as social problems. According to Botsman and Rogers (2010), the Great Pacific Garbage Patch in the Pacific Ocean is composed of many single-use containers such as plastic bags, in addition to other discarded materials, and it has been estimated to be as large as a continent. To-go cups (e.g. coffee) are essentially made of paper, yet they incur a thin coating of plastic or wax which makes the recycling process much more difficult than office paper (Earth911, 2014). Despite company claims and the presence of store recycling bins in many outlets, many to-go cups actually go into landfills and do not get recycled (Johnson, 2015). These different containers need also considerable amounts of natural resources (e.g. oil) to be produced and transported.

The situation is deteriorating in Western industrialized countries but also in emerging fast-growing countries especially in Asia (e.g. China). In an attempt to tackle escalating waste generation issues from single-use containers, a ban came into effect on June 1 , 2008 that prohibited stores throughout China from giving out free plastic bags. Despite avoiding the consumption of at least 40 billion bags and saving an equivalent of 1.6 million tons of petroleum (Worldwatch Institute, 2013), this ban did not affect the use of plastic bags at restaurants for take-out meals, nor did it extend to to-go cups or single-use boxes (e.g. in cardboard, or paper) (Upton, 2013). Also, while, state-enforced regulation tends to be effective in China (Zhang and Wen, 2008), it is debatable whether a government ban could be as effective in a Western context.

While responsibilities to curb garbage from single-use containers are equally shared between policy-makers, businesses, local authorities and consumers, this study focuses on consumers and explores how to instill a change in consumers' behavior. Specifically, we advance the theory of planned behavior (TPB) to explain consumers' consumption of reusable containers. This study makes three contributions to the literature. First, distinct from past research on pro-environment behavior, this study focuses on reusable containers consumption and explores how to encourage consumers to use undisposable multi-usage containing solutions such as thermal bottles, coffee mugs, refillable bottles or reusable bags. To the best of our knowledge, this is the first study dedicated to exploration of consumer reusable container consumption behavior. Our second contribution is to augment the TPB model with two additional constructs which are highly relevant for predicting reusable containers consumption. The first is perceived contextual factors which are typically excluded from the TPB. The second is consumer motivation, which we propose as clearly distinct from intentions, as opposed to being conflated with them as theorized (Ajzen, 1991). Our third contribution is the examination of variations in the proposed consumer behavior model between Asian and Western cultures.

\section{Background research}

Four types of alternative containing solutions may be distinguished: (1) single-use; (2) disposable multi-use; (3) hybrid-use; and (4) undisposable multi-use. The three former types are provided with the content in them upon purchase. In contrast, undisposable multi-use containing solutions are sold without any content in them upon purchase and are therefore not in their endof-life but rather at the beginning of their lifecycle. They constitute a generic multi-use packaging which is specifically conceived to be reused over time (Numata and Managi, 2012) and include containers of liquid (e.g. beverages) or solid (e.g. fabric) elements. Examples include thermal bottles, drinking bottles or coffee mugs.

Historically this latter category prevailed but was nonetheless restrictive in that it required maintenance and transportation from organizations and consumers, and often lacked mobility capacities. For example, coffee mugs need to be rewashed, repaired if broken, carried and stored. This may represent several hindrances for the sale of contents. First, reuse practices may generate cues on the container which trigger negative contamination and decrease the value of the product (Nemeroff and Rozin, 1994). According to the laws of sympathetic magic (Frazer [1890] 1959; Mauss [1902] 1972; Tylor [1871] 1974), which has been amply used as a theoretical framework in consumer behavior studies (e.g. Roux and Korchia, 2006), when consumers become cognizant that another consumer has previously touched a product, their evaluation of and purchase intentions for the product decrease (Rozin et al., 1994).

Second, although consumers have more free time than previous generations, there is an increasing perception of time shortage (Lambert, 2015). This is because consumers not only consume products and services but they also contribute to their production and delivery (Denegri-Knott and Zwick, 2012; Ritzer and Jurgenson, 2010). Consumers "prosume" or perform "shadow work" whenever they do jobs that used to be done by paid employees but have now been outsourced to the consumer (e.g. booking a flight, pumping gas; Ritzer, 2014; Lambert, 2015). Prosumption processes involve increasingly single-use containing solutions for convenience and efficiency.

Third, and related to the second point, with the conjunction of increased time pressure and technological advances, modern consumption behaviors has evolved toward an alarming increase in waste due to the disposal of containers (Accorsi et al., 2014) particularly for consumer goods purchases, and the growing demand for restaurant, fast-food, catered and take-out meals.

In order to increase sales of various types of contents, by decreasing potential perceptions of negative contamination, improving the efficiency of business processes and take advantage of technological advances, increased recourse to single-usage containers has given way to "irrationalities of rationality" such as growing disposal of finite resources in a wasteful manner. One of such irrationalities resides in the increasing recourse to single-use containers which inherently increase waste production. Influencing consumer behavior to favour pro-environmental behavior constitutes an interesting approach to curb waste production (Leisman et al., 2013). The Theory of Planned Behavior (TPB) has been used to a great extent to study multiple forms of environmental consumer behavior (e.g. Bamberg and Möser, 2007; Klöckner, 2013; De Leeuw, Valois, Ajzen, and Schmidt, 2015). Drawing on the proven reliability and validity of this theoretical framework, we use an adapted version of the TPB in order to model the consumer process underlying reusable container consumption, with the purpose of identifying specific variables to promote such a behavior.

\section{Conceptual model}

Ajzen (1991)'s Theory of Planned Behavior (TPB), has been one of the most influential theories in explaining and predicting a wide range of behaviors. TPB is the extension of Ajzen and Fishbein (1980)'s Theory of Reasoned Action (TRA).

\footnotetext{
5 The expression is borrowed from George Ritzer's article "Shadow work and prosumption" written on August 12, 2015 and accessible on: https://georgeritzer. wordpress.com/author/gritzer2012/ (retrieved 11-03-2016).
} 


\subsection{Attitude, subjective norms, and perceived behavioral control}

According to the TRA, the closest antecedent of behavior is intention, which in turn is determined by Attitude (A) and Subjective Norms (SN). Attitude refers to the degree to which a consumer has a favorable or unfavorable evaluation of the behavior of interest. Subjective Norms refer to the consumer's beliefs about whether important others (e.g. peers) approve or disapprove of the behavior. Acknowledging that most human behavior is typically subject to hindrances, Ajzen (1991) introduced TPB that generalizes TRA by adding a third perception: Perceived Behavioral Control $(\mathrm{PBC})$, which refers to a person's perception of the ease or difficulty of performing the behavior of interest.

The TPB is framed within an expectancy-value framework so that attitude, SN and PBC are the product of a set of attitudinal, normative, and control beliefs, interacting respectively with the perceived importance of those attitudinal, normative and control beliefs (Ajzen, 1991). For example, attitude is the product of attitudinal beliefs and the person's subjective evaluation of the desirability of the outcome. However, these sets of antecedents are rarely used in the framework of environmental studies, where measurement is rather limited to attitude, SN and PBC constructs, but does not extend to belief and importance antecedents (De Groot and Steg, 2007). Instead, the common tendency is to use general determinants such as value orientations (e.g. Finch et al., 2015) or, general environmental concerns (Stern and Dietz, 1994; De Groot and Steg, 2007) as antecedents to the TPB. Ajzen and Fishbein (1980) acknowledged that such general determinants can have important indirect effects on behavior via their influence on the perception and evaluation of situation-specific attitudinal, normative and control beliefs, and consequently, on attitudes, SN and PBC. While the effect of concerns and value orientations have been already proven to be significant determinants (sic), little attention has been devoted to the fundamental construct of motivation. The fact that this has been rarely investigated in environmental studies is remarkable given the highly influential effect of motives in determining intentions and subsequent behavior (Larsen and Buss, 2008).

Moreover, motivation, in contrast to typically situationunrelated determinants such as value orientation frameworks, environmental concerns, and more broadly moral and normative concerns (De Groot and Steg, 2007; Stern and Dietz, 1994; Nordlund and Garvill, 2002), may be considered as both situation-specific and general predisposition (Larsen and Buss, 2008; Koestner and McClelland, 1990). Although some studies have analyzed proenvironmental behavior through the perspective of the TPB (Chan, 1998; Davis et al., 2006; Feng and Reisner, 2011; Tonglet et al., 2004), no study - to the authors' knowledge - has examined the relationship between motivation and environmental behavior within a TPB framework. We propose that the dual aspect inherent to motives as being both situation-specific and general predisposition may enrich previous findings solely focused on either situation-specific or general predisposition effect on the TPB.

\subsection{Intentions and motivation}

In classic modeling on consumer behavior such as TRA, TPB, and also in other models such as Bagozzi and Warshaw (1990)'s theory of trying, intentions are generally conflated with motivation. Behavioral intentions are conceptualized as motivational factors that capture how hard people are willing to perform a behavior (Ajzen, 1991), or are willing to try to perform a behavior (Bagozzi and Warshaw, 1990). However, motivation is distinctive from intentions. In 2002, Icek Ajzen updated several constructs of the TPB and defined intentions as an indication of an individual's readiness to perform a given behavior. In contrast, motivation refers to internal states that arouse and direct behavior toward specific objects or goals (Larsen and Buss, 2008). More importantly such states are often caused by a deficit, a lack of something so that motives are often based on needs or states of tension caused by a deficit within a person (Larsen and Buss, 2008). To illustrate the directional nature of motivation, classic motivational theory often refers to a motive as a "driver" (McClelland, 1961). Therefore, motivation drives behavioral intentions to enact a certain behavior presumed to fulfill the need. For example, when a person has not eaten for many hours, she is motivated by hunger due to the lack of nutrients in the body, which triggers intentions to reduce that lack by performing specific behaviors known to decrease the tension, such as eating. In conclusion, motivation and intentions should therefore be distinguished from each other.

\subsection{Behavior}

TPB suggests that the most influential predictor of behavior is behavioral intentions because typically a person does what she intends to do. Past meta-analyses demonstrated a strong and significant link between intentions and behavior (Bamberg and Möser, 2007; Klöckner, 2013). Thus, it is reasonable to expect a positive relationship between intentions and behavior.

\subsection{Contextual factors}

In addition to intra-personal factors (e.g. attitudes), contextual aspects are increasingly more relevant for explaining proenvironmental behaviors (Steg and Vlek, 2009; Fielding et al., 2013). For example, the availability of recycling facilities, the market supply of goods, pricing regimes, or the quality of public transportation services, have been identified as useful predictors of consumers' engagement in pro-environmental behavior (Santos, 2008; van Diepen and Voogd, 2001; Vining and Ebreo, 1992). According to Campbell-Arvai et al. (2014), asymmetric intervention ("nudges") in consumers' contexts are even more important than value orientation or information provision, in motivating choices with positive environmental outcomes. The introduction of smart water metering technology in households of South East Queensland, in Australia, led to reduced levels of consumption (Fielding et al., 2013). Overall, consumer perception of contextual factors leads to an increase or decrease in behavior through intra-personal constructs (Steg and Vlek, 2009). Consumer perception of context, as being both an intra-psychic and an environmental variable, might therefore fit well into the TPB model, by possibly improving its predictive validity.

\subsection{Culture}

Many theories, including the TPB, have been developed by Western researchers thus are rather applicable in Western cultural contexts (Triandis, 1995; Hofstede, 1999; Adler, 2008). It may therefore be expected that the hypothesized relationships pertaining to the TPB function differently for Western and for Asian consumers. Moreover, the current study augments the TPB by motivation and context, and motivational theories are not universal, but rather reflect the value systems of Americans (Adler, 2008). Thus, differences might emerge with Asians who hold a different value system than Americans (Robbins and Judge, 2008). Although culture, as an intangible element (Satterfield et al., 2013), is hard to measure, we posit that it has an influence on consumer behavior. Therefore, we propose culture (Asian vs. Western) as a moderating variable on the adapted TPB framework. We expect that since Asian consumers tend to have an interdependent self-construal (Markus 
and Kitayama, 1991), their consumption of reusable containers will be more likely to be influenced by subjective norms and perceived behavioral control, while context is expected to drive more strongly their intentions and behavior through motives. Westerners, on the other hand, have a more independent self-construal (Markus and Kitayama, 1991), which leads them to think of themselves as autonomous from others and therefore context may more strongly influence their intentions and actions related to reusable container consumption, through intra-psychic variables related to the self, such as attitudes.

\section{Hypotheses development}

\subsection{Contextual factors}

Studies have demonstrated a positive relationship between perceived contextual factors (e.g. availability of facilities, supply and quality of goods, legislation, pricing) and individual proenvironmental motivation (Fielding et al., 2013; Campbell-Arvai et al., 2014). In fact, contextual elements might be conceived to facilitate or constrain the fulfillment of a need, the decrease of a tension, hence the emergence of a motive. For example, past research emphasized that reduction in car use, which could also decrease money shortages, may be more easily enacted if feasible alternatives to car use are perceived to be available (Steg and Vlek, 2009). More stringent regulations are instrumental to direct consumers toward more ecological practices as an attempt to fulfill their need for stability and safety (Paulraj, 2009). For instance, Numata and Managi (2012) found that consumers are concerned about container flaws and stains which signal contamination and therefore lack of hygiene or safety. Yet, if consumers perceive that the overall quality of the reusable container is at least as clean or safe as other types of containers, they may be more willing to consider reusable containers (Numata and Managi, 2012). Therefore:

H1. Consumers' perception about favorability of the context is positively related to motivation to consume reusable containers.

Attitudes are structures in long-term memory that are products of a multi-stage process, and each of these stages may be influenced by contextual elements (Tourangeau and Rasinski, 1988). Favorable contextual factors should have a positive effect on attitudes. Olli et al. (2001) found that contextual elements facilitating environmental behavior are positively correlated to environmental attitudes. Steg and Vlek (2009) claim that the introduction of recycling facilities may result in more positive attitudes towards recycling as it becomes more convenient. In China, Liu et al. (2010) found that the promotion of pro-environmental attitudes among residents of protected areas is more effective when changes are introduced in a context related to those residents (e.g. improving environmental education, establishing community co-management and launching substitute sources of cash for traditional cultivation). Contextual elements tend actually to explain even higher shares of variances in attitudes than sociodemographic variables (Vorkinn and Riese, 2001; Olli et al., 2001). We therefore hypothesize that:

H2. Consumers' perception about favorability of the context is positively related to attitudes toward reusable containers consumption.

It is generally accepted that favorable contextual elements have a direct effect on perceived behavioral control (e.g. Jaworski, 1988). Ajzen (2002) emphasized that PBC denotes a subjective degree of control over the performance of a behavior and suggested therefore that $\mathrm{PBC}$ "should be read as perceived control over the performance of a behavior". Perception of such control is eminently influenced by elements that are part of the consumer's environment. Several studies emphasized that environmental factors may be facilitators or constraints and therefore exert direct influence on consumers' perception of their level of control over performing a given action (Vining and Ebreo, 1992; Poortinga et al., 2004; Steg et al., 2005). For example, if constraints (e.g. pricing, legislation) are too severe, consumers may feel that they have little control over the performance of an environmental behavior, because the behavior may be too costly, too time-consuming, too effortful and high motivational levels would make little difference (Corraliza and Berenguer, 2000; Guagnano et al., 1995). Therefore:

H3. Consumers' perception about favorability of the context is positively related to perceived behavior control over reusable containers consumption.

\subsection{Motivation}

Despite TPB's extensive use and attractive parsimonious account of pro-environmental behavior, there are concerns about its incompleteness (Gifford, 2014). For instance, moral norms was identified and empirically demonstrated as an important missing construct in TPB when applied to behaviors with a clear moral dimension (Klöckner, 2013; De Leeuw et al., 2015). Another missing construct is motivation, mainly because it is often conflated with intentions. Yet, several studies which deliberately considered the two constructs separately, found a direct impact of motives on intentions in a TPB framework (Wall et al., 2008). In the present study we consider motivation as an additional proximal antecedent of behavioral intentions.

Motivation has been identified as a direct antecedent to the social-cognitive construct of intentions in the TPB framework (Grano et al., 2008; Lee et al., 2010). Applied to the focal behavior, motives reflect consumers' internal state that arouses after identification of a deficit and need, and thus directs behavior toward reusable container consumption. The motive may be situationspecific, such as using reusable bags instead of buying plastic bags in order to save money, as an attempt to alleviate money deficit. Or it may be of a more general concern, such as using reusable bags as a personal challenge to increase personal mastery and manipulation of objects and one's environment (i.e. need for achievement [McClelland, 1985]). Therefore:

H4. Consumers' motives to consume reusable containers relate positively to reusable container consumption intentions.

Since motives direct intentions toward behaviors which are expected to fulfill a need, deductive logic dictates that heightened motivation exert a direct influence on the consumer's perception of the attractiveness of the behavior hence an influence on her attitude toward the behavior. Thus:

H5. Consumers' motives to consume reusable containers relate positively to favorable attitudes toward reusable container consumption.

\subsection{Theory of planned behavior}

In accordance with previous support for TPB relationships in environmental behaviors (Bamberg and Möser, 2007; Klöckner, 2013; De Leeuw et al., 2015), we hypothesize an effect of attitude (H6), Perceived Behavioral Control (PBC) (H7), and Subjective Norms (SN) (H8) on intentions to consume reusable containers. Eventually, we also expect that intentions influence positively 
actual reusable container consumption behavior (H9). The conceptual model is shown in Fig. 1.

\section{Methodology}

\subsection{Measurement scales}

A questionnaire was developed and pre-tested on 180 students in a Canadian and a Chinese university respectively. The context measure was developed and pre-tested by the authors. The motivation measure was adapted from Kollmuss and Agyeman (2002). The attitude measure was adapted from Sparks and Shepherd (1992). Subjective norms were measured using Whitmarsh and O'Neill (2010)'s scale. A PBC scale was derived from Sparks and Shepherd (1992). Intentions toward reusable container consumption assessed intentions to 1) use reusable containers, (2) consider the use of reusable containers, and (3) consider switching to use reusable containers. A set of specific behaviors (i.e. reusable container consumption) were initially selected based on their frequency (as reported by Accorsi et al., 2014) and their relevance to the four countries where the data were gathered. This is because we seek to test for the moderating effect of culture on the full structural model thus the types of reusable containers used in the study must be common to all 4 countries. The final scope of specific behaviors was then confirmed through the pretest and was limited to bags, cups (i.e. mugs and tumblers) and bottles. Item wording and anchor points can be found in Appendix A. All variables were measured with a seven-point Likert scale.

\subsection{Data and methods}

Altogether 1221 responses were collected from Western ( $n=549)$ and Asian $(n=672)$ consumers. Females made up $51.8 \%$ of respondents and $71.3 \%$ lived in cities. Almost half of the respondents (45\%) had a Bachelor's degree. On average, respondents were 30.8 years old. Culture was identified through a proxy variable that indicated in which country the respondents filled in the survey (28.7\% in China; $26.4 \%$ in South Korea; $25.6 \%$ in Canada and $19.3 \%$ in the United States). This variable is strongly associated with the country in which respondents live and also with the country in which they were born. Therefore, using the country in which they answered the survey is a good proxy for cultural background since it captures both the nurturing aspect of where consumers were born and raised as well as the more structural aspect of where consumers live and evolve which also influence cultural perceptions. In the forthcoming multigroup analysis, data from China and South Korea were grouped together as Asian and data from Canada and Unites States were grouped together as Western.

\section{Analysis and results}

\subsection{Common method variance}

We used an a priori technique to decrease common method variance (CMV) by randomizing the questions. We also implemented an a posteriori technique to rule out CMV by conducting Harman's single-factor test (Podsakoff et al., 2003). A single-factor CFA yielded an extremely poor fit $\left(\chi_{(458)}^{2}=6069.2931, \chi^{2} / d f=13.25\right.$ $(>5), \mathrm{CFI}=0.622, \mathrm{GFI}=0.777, \mathrm{AGFI}=0.743, \mathrm{RMSEA}=0.100[.091$, .109]). These results confirm that CMV is not of concern and not likely to confound the interpretations of the results.

\subsection{Confirmatory factor analysis, validity and reliability}

We validate the seven-factor measurement model by means of CFA using EQS 6.2 and the robust Maximum Likelihood Method (ML-r). Global fit indices are good (Table 1). Both the Asian and the Westerner sample show acceptable fit. All the items loaded significantly on their constructs $(p<0.001)$ and factor loadings range from 0.500 to 0.915 . Cronbach's alphas $(\alpha)$ and Coefficients of Reliability (CR) for all constructs are greater than 0.70 , and the average variance extracted (AVE) is always greater than 0.50

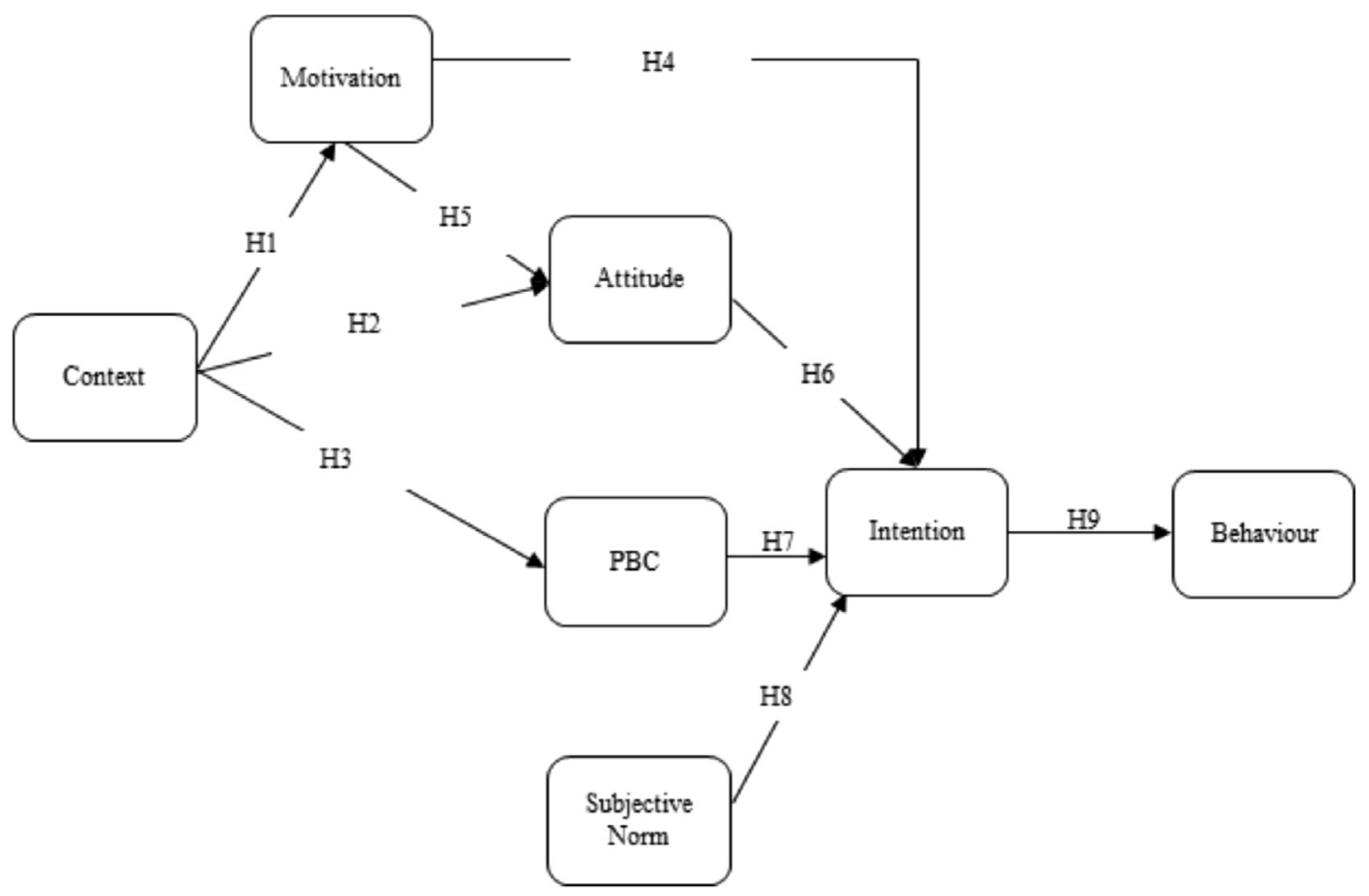

Fig. 1. Conceptual model. 
Table 1

Confirmatory factor analysis: global measures of fit.

\begin{tabular}{|c|c|c|c|c|c|c|c|c|}
\hline & $\chi^{2}$ & d.f. & $\chi^{2} / \mathrm{d} f$ & RMSEA & RMSEA Confidence Interval & CFI & GFI & AGFI \\
\hline Total $(n=1221)$ & 1515.3453 & 437 & 3.47 & 0.050 & $(0.047 ; 0.053)$ & 0.927 & 0.948 & 0.937 \\
\hline Asians $(n=672)$ & 1261.4003 & 437 & 2.89 & 0.053 & $(0.045 ; 0.060)$ & 0.921 & 0.929 & 0.914 \\
\hline Westerners $(n=549)$ & 822.9425 & 437 & 1.88 & 0.040 & $(0.031 ; 0.048)$ & 0.916 & 0.958 & 0.949 \\
\hline
\end{tabular}

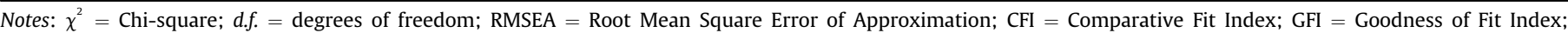
AGFI $=$ Adjusted Goodness of Fit Index.

(Bagozzi and Yi, 1988) (Table 2). Discriminant validity is confirmed since the shared variance between each pair of factors is always inferior to the corresponding AVE (Fornell and Larcker, 1981), except for two cases; the intentions-PBC and the intentionsattitudes correlations. However, both correlations remain below the critical value of $|.85|$ (Kenny, 2012). Besides, discriminant validity was further assessed via a pairwise restriction of models (Anderson and Gerbing, 1988), where the correlation between each pair of factors was fixed to equal 1.0 and the significance of chisquare change was tested. All chi-square changes were significant, showing better fit for the model without these restrictions.

\subsection{Structural analysis}

Analysis of the full structural model for the whole sample was performed using EQS 6.2 and the robust Maximum Likelihood Method (ML-r). Both global and local fit indices were good. The results of the structural paths are reported in column 2 and 3 of Table 3. The results of the structural model show that different intra-psychic variables contribute differently to reusable container consumption. The results suggest that the TPB framework adequately predicts intentions and behavior since attitude, PBC and SN have a directional and significant influence on intentions and that intentions predict behavior accordingly, which collectively support H6-9. As hypothesized, the results show that the inclusion of perceived contextual factors has a direct and significant effect on both attitude, and especially PBC, which lends support to $\mathrm{H} 2$ and $\mathrm{H} 3$, respectively. In addition, motivation is a clearly distinct construct from intentions (see Tables 2 and 4). Context is an important antecedent to motivation, since it explains almost half (48\%) of motive construct variance, which supports H1. Also, motivation impacts significantly both intentions and attitude, supporting $\mathrm{H} 4$ and $\mathrm{H} 5$, respectively. The results are shown in Fig. 2.

\subsection{Multigroup invariance analysis}

Culture is considered as a moderating variable on the hypothesized relationships in the model. We followed Steenkamp and Baumgartner (1998)'s procedure to ensure that the model structure and the hypothesized relationships among the constructs under study were invariant across the Asian and the Westerner sample. Configural, metric and structural invariance tests were thus performed on the full sample $(N=1221)$ (Table 4$)$. Configural invariance tested whether the pattern of fixed and free parameters is the same for the two groups and metric invariance examines the extent to which the factor structure is statistically invariant between the groups. Both prerequisites were met $\left(\Delta \chi^{2}\right.$ $(77)=97.78, p=0.06$ ) (Table 4). Consequently, the model can be meaningfully compared across groups. Structural invariance was performed to determine whether regression weights for each structural path are statistically invariant between the groups. All structural paths that were invariant were constrained between the two groups. Each constraint was then entered one by one keeping previous invariant paths constrained while freeing non- invariant paths. The results are shown in the last three columns of Table 3.

The multigroup analysis results show that some relationships vary across cultures. Within the TPB framework, attitude appears a significantly stronger predictor of intentions for Westerners than for Asians. When newly introduced variables are considered, context appears to be a much stronger predictor of attitude for Westerners than for Asians and this result should be linked to the previous relationship. Although the influence of context on motivation does not significantly differ across the two cultural groups, there is a statistically significant and directional effect of motives on intentions in the Asian sample only. Additional $t$-tests

Table 2

Psychometric properties.

\begin{tabular}{|c|c|c|c|}
\hline & \multicolumn{3}{|c|}{ Estimates } \\
\hline & Total & Asian & Western \\
\hline \multicolumn{4}{|c|}{ Motivation } \\
\hline$\mu$ & 5.01 & 5.05 & 4.96 \\
\hline SD & 1.34 & 1.31 & 1.38 \\
\hline AVE & 0.607 & 0.630 & 0.572 \\
\hline$\alpha$ & 0.863 & 0.887 & 0.840 \\
\hline CR & 0.860 & 0.871 & 0.841 \\
\hline \multicolumn{4}{|c|}{ Context } \\
\hline$\mu$ & 5.25 & 5.26 & 5.23 \\
\hline SD & 1.29 & 1.34 & 1.24 \\
\hline AVE & 0.733 & 0.773 & 0.647 \\
\hline$\alpha$ & 0.878 & 0.908 & 0.836 \\
\hline $\mathrm{CR}$ & 0.892 & 0.911 & 0.846 \\
\hline \multicolumn{4}{|c|}{ Attitude } \\
\hline$\mu$ & 6.11 & 5.98 & 6.28 \\
\hline SD & 0.90 & 0.93 & 0.83 \\
\hline AVE & 0.592 & 0.584 & 0.601 \\
\hline$\alpha$ & 0.911 & 0.911 & 0.905 \\
\hline CR & 0.910 & 0.907 & 0.912 \\
\hline \multicolumn{4}{|c|}{ Social Norm } \\
\hline$\mu$ & 5.92 & 5.92 & 5.91 \\
\hline SD & 1.04 & 1.04 & 1.03 \\
\hline AVE & 0.742 & 0.763 & 0.718 \\
\hline$\alpha$ & 0.920 & 0.928 & 0.908 \\
\hline CR & 0.920 & 0.928 & 0.910 \\
\hline \multicolumn{4}{|c|}{ Perceived Behavioral Control } \\
\hline$\mu$ & 5.72 & 5.74 & 5.70 \\
\hline SD & 0.96 & 0.95 & 0.96 \\
\hline AVE & 0.523 & 0.557 & 0.470 \\
\hline$\alpha$ & 0.747 & 0.791 & 0.705 \\
\hline CR & 0.765 & 0.788 & 0.723 \\
\hline \multicolumn{4}{|c|}{ Intentions } \\
\hline$\mu$ & 5.98 & 5.90 & 6.07 \\
\hline SD & 1.05 & 1.01 & 1.09 \\
\hline AVE & 0.528 & 0.524 & 0.548 \\
\hline$\alpha$ & 0.834 & 0.835 & 0.833 \\
\hline CR & 0.768 & 0.766 & 0.783 \\
\hline \multicolumn{4}{|c|}{ Behavior } \\
\hline$\mu$ & 3.76 & 3.99 & 3.48 \\
\hline SD & 1.35 & 1.35 & 1.30 \\
\hline AVE & 0.416 & 0.418 & 0.414 \\
\hline$\alpha$ & 0.844 & 0.866 & 0.810 \\
\hline CR & 0.849 & 0.851 & 0.847 \\
\hline
\end{tabular}

Notes: $\mu=$ Mean [Scale 1-7]; SD = standard deviation; AVE = Average Variance Extracted; $\alpha=$ Cronbach's alpha; $\mathrm{CR}=$ Coefficient of Reliability. 
Table 3

Structural equation model: standardized path estimates and goodness of fit indices.

\begin{tabular}{|c|c|c|c|c|c|c|c|c|c|}
\hline \multirow[t]{2}{*}{ Hypotheses } & \multicolumn{2}{|c|}{ Total $(n=1221)$} & \multicolumn{2}{|c|}{ Asians $(n=672)$} & \multicolumn{2}{|c|}{ Westerners $(n=549)$} & \multicolumn{3}{|c|}{ Model differences } \\
\hline & Stand. $\beta$ & $t$-value & Stand. $\beta$ & $t$-value & Stand. $\beta$ & $t$-value & $\overline{\Delta \chi^{2}}$ & $\Delta d f$ & $\overline{p \text {-value }}$ \\
\hline $\mathrm{H} 1: \mathrm{CON} \rightarrow \mathrm{MOT}$ & 0.690 & $14.763^{* * *}$ & 0.641 & $13.740^{* * * *}$ & 0.622 & $7.348^{* *}$ & 0.23 & 1 & n.s. \\
\hline $\mathrm{H} 2: \mathrm{CON} \rightarrow \mathrm{ATT}$ & 0.373 & $6.771^{* *}$ & 0.267 & $4.597^{* *}$ & 0.594 & $6.033^{* *}$ & 7.43 & 1 & $p<.01$ \\
\hline $\mathrm{H} 3: \mathrm{CON} \rightarrow \mathrm{PBC}$ & 0.657 & $12.390^{* * *}$ & 0.577 & $10.498^{* * *}$ & 0.791 & $6.823^{* *}$ & 0.39 & 1 & n.s. \\
\hline $\mathrm{H} 4: \mathrm{MOT} \rightarrow \mathrm{INT}$ & 0.273 & $5.429^{* *}$ & 0.332 & $6.567^{* *}$ & -0.068 & -0.943 (n.s.) & 15.09 & 1 & $p<.001$ \\
\hline $\mathrm{H} 5: \mathrm{MOT} \rightarrow \mathrm{ATT}$ & 0.105 & 1.815 (n.s.) & 0.124 & $1.993^{*}$ & 0.072 & 0.876 (n.s.) & 0.26 & 1 & n.s. \\
\hline H6: ATT $\rightarrow$ INT & 0.286 & $6.480^{* *}$ & 0.171 & $3.641^{* *}$ & 0.369 & $3.817^{* *}$ & 3.84 & 1 & $p<.05$ \\
\hline $\mathrm{H} 7: \mathrm{PBC} \rightarrow \mathrm{INT}$ & 0.440 & $8.779^{* *}$ & 0.394 & $7.550^{* *}$ & 0.212 & $2.287^{* *}$ & 1.89 & 1 & n.s. \\
\hline $\mathrm{H} 8: \mathrm{SN} \rightarrow \mathrm{INT}$ & 0.218 & $5.864^{* *}$ & 0.263 & $6.218^{* *}$ & 0.184 & $2.255^{* *}$ & 0.34 & 1 & n.s. \\
\hline H9: INT $\rightarrow$ BEH & 0.363 & $8.002^{* *}$ & 0.426 & $7.614^{* *}$ & 0.355 & $4.171^{* *}$ & 0.60 & 1 & n.s. \\
\hline \multirow[t]{7}{*}{ Global goodness of fit indices } & $\chi^{2}$ & 1841.36 & $\chi^{2}$ & 1622.51 & $\chi^{2}$ & 901.47 & & & \\
\hline & $\mathrm{d} f$ & 448 & $\hat{\mathrm{d} f}$ & 448 & $\hat{\mathrm{d} f}$ & 448 & & & \\
\hline & CFI & 0.906 & CFI & 0.887 & CFI & 0.901 & & & \\
\hline & GFI & 0.933 & GFI & 0.901 & GFI & 0.951 & & & \\
\hline & AGFI & 0.921 & AGFI & 0.884 & AGFI & 0.942 & & & \\
\hline & RMSEA & 0.050 & RMSEA & 0.063 & RMSEA & 0.043 & & & \\
\hline & RMSEA C.I. & $0.044 ; 0.056$ & RMSEA C.I. & $0.055 ; 0.070$ & RMSEA C.I. & $0.034 ; 0.051$ & & & \\
\hline
\end{tabular}

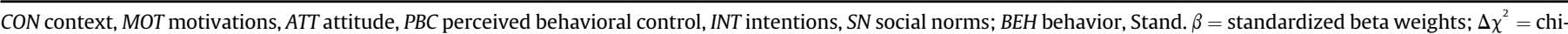

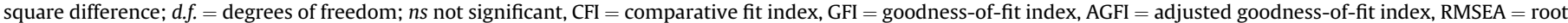
mean square error of approximation, C.I. = confidence interval

${ }^{*} \mathrm{p}<.05,{ }^{* *} \mathrm{p}<.01,{ }^{* * *} \mathrm{p}<.001$.

Table 4

Full model: configural and metric invariance.

\begin{tabular}{|c|c|c|c|c|c|c|c|c|c|}
\hline & $\chi^{2}$ & d.f. & RMSEA (C.I.) & CFI & GFI & AGFI & $\Delta \chi^{2}$ & $\Delta$ d.f. & $p$ value \\
\hline Configural & 2078.52 & 896 & $0.034[0.028 ; 0.039]$ & 0.920 & 0.942 & 0.965 & - & - & - \\
\hline Metric & 2176.30 & 973 & $0.034[0.028 ; 0.039]$ & 0.915 & 0.939 & 0.964 & 97.78 & 77 & 0.06 \\
\hline
\end{tabular}

Note: No partial metric invariance model was needed since all items were invariant across both samples.

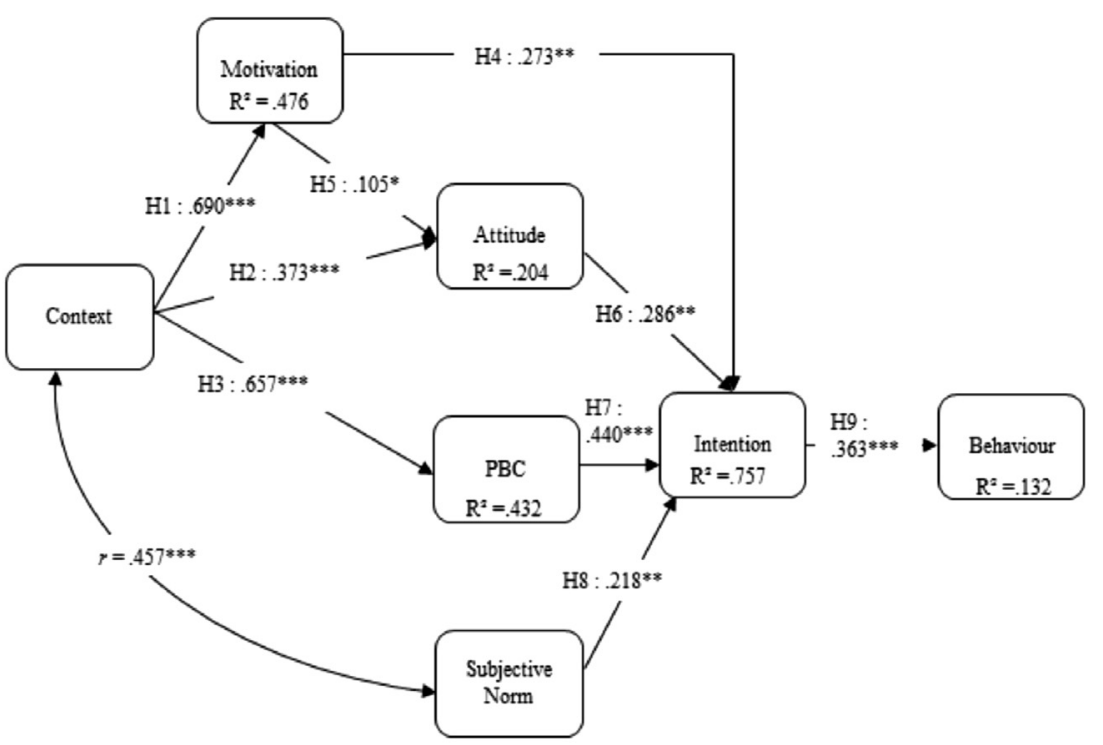

Note: The $\mathrm{R}^{2}$ values represent the proportion of variance of the variable that is being explained by direct or indirect antecedents

$* \mathrm{p}<.05, * * \mathrm{p}<.01, * * * \mathrm{p}<.001$

Fig. 2. Conceptual model with values. 
further revealed significant differences between groups on the context-PBC as well as the SN-intentions relationships, with Westerners scoring higher on the former and Asians scoring higher on the latter. However, these results were marginally significant and not supported by chi-square tests.

\section{Conclusions and discussion}

An insight into how different intra-psychic variables simultaneously affect the consumption of reusable containers and whether their effects differ across cultures is just emerging. The current study represents a step in this direction. This research contributes to the rising awareness that firms and consumers alike need to change the current pattern of reusable containers consumption (Leisman et al., 2013) and that there are potentially cross-cultural differences in behavior (Adler, 2008; Triandis, 1995; Hofstede, 1999; Robbins and Judge, 2008).

The results of the present study confirm TPB as an appropriate framework for representing consumers' reusable containers consumption. The results also support addition of the context variable as an important predictor of perceived behavioral control and attitude. Further, the findings support addition of the motivation variable, which has context as a strong antecedent, and attitude and intention as outcomes. Our results provide empirical evidence for importance of distinguishing motivation and intentions (Wall et al., 2008). More concretely, consistent with past research which emphasized the importance of adding motives in the TPB framework (Lee et al., 2010; Grano et al., 2008), we confirm that the addition of motivation contributes well to the explanation of intentions. In fact, in previous studies (e.g. De Leeuw et al., 2015), the proportion of variance explained for intentions is $69 \%$ at most, but with the insertion of motives (and indirectly, context) our model explains more than three quarters of the variance in intentions.

Context has a strong influence on both motivation and perceived behavioral control, which highlights the importance of consumers' perceptions of environmental elements that may facilitate or inhibit their recourse to reusable containers. These perceptions are important to modulate because they impact directly motivation and perceived behavioral control. Perceived behavioral control has the strongest impact on intentions, which is intrinsically noteworthy and is consistent with literature (De Leeuw et al., 2015). Out results are in line with Van Rompay et al. (2012) who showed that motivations are closely related to environmental factors in retailing. Our findings further stress the importance of creating situations which facilitate the consumption of reusable containers and complicate the recourse to single-use ones. In so doing, consumers will perceive reusable containers use as less inconvenient which will strongly impact their intentions to consume multiusage containers. Besides, consumers will also feel more motivated to engage in reusable containers consumption. In fact, in line with a Beckerian utility framework, as less scarce option, it may appear as a more practical solution with increased levels of utility and benefits (Lamberton and Rose, 2012).

Culture moderates these relationships. The results suggest that the impact of motives on intentions is limited to the Asian sample and is nonsignificant in the Western sample. Therefore, the modulating of context and its impact on motivation is likely to increase intentions among Asian consumers. In contrast, Westerners seem to be more influenced by context to intend use of reusable containers, through attitudes. Compared to Asians, a change in context variables will more effectively induce a change in
Westerners' positive predisposition to intend reusable container consumption and subsequently perform such behavior. Two culturally marked routes of influence emerge, both originating from the context variable. For Asians (Westerners), context impacts more strongly reusable containers consumptions intentions and behavior via motivation (attitudes). A third route to reusable container consumption from context to behavior through PBC operates equivalently across both groups. Our findings respond to previous calls in the literature, particularly from Ramasamy and Yeung (2009), for more systematic consumer research on the topic of cross-cultural consumer behavior.

\section{Managerial and decision-making implications}

The results show that context has a strong influence on motivation, perceived behavioral control, and attitudes. This finding highlights the centrality of consumers' perceptions of environmental elements that may facilitate or inhibit their recourse to reusable containers. The perception of the large availability of single-use to-go cups combined with the perceived awkwardness or inefficiency of asking cashiers to refill a thermal bottle, for example, may constitute a contextual hindrance. In an attempt to change consumer behavior, managers need to increase consumers' perception of a context that is reuse-friendly. Managers could design more flexible operational processes in which consumers are provided with more leeway to manipulate reusable instead of single-use containers. Managers could proactively ask consumers for reusable containers and propose a price incentive for consumers who take away meals or to-go beverages in their own containers. Besides, there should be an increased tendency to offer reusable containers instead of single use ones. Several studies show that this is much valued by consumers who appreciate to receive packaging that not only protects their content but which may also be reusable in the future (Ipsos InnoQuest, 2013).

We believe that managers may benefit from concurrence of policy-makers and political decision-makers in creating an impetus for reusable container consumption. In fact, legislation is an important element in consumers' contexts (Guagnano et al., 1995), and the importance of the context variable, found in this study, suggests that enacting laws and regulations which encourage reusable containers consumption could have a very strong effect in changing consumer behavior. As such, given that the influence of context for Westerners is more strongly driven by attitudes, the laws and regulations should be positively framed such as by emphasizing the benefits of reusable containers and by facilitating situations for the use of reusable containers. For Westerners laws and regulations should rather not be negatively framed (e.g. ban) since such framing may be counter-productive. In the West, consumers have a more independent view of their self as an entity that is distinct, autonomous, self-contained, and endowed with unique dispositions, so that they are more likely to experience ego-focused emotions (Hofstede, 1999; Markus and Kitayama, 1991). Therefore, negative framing may translate into negative personal attitudes because of a perception of restraint of the self or curbing of the ego, which could subsequently dampen reusable container consumption intentions and behavior. In collectivist cultures such as Asian cultures, where people hold interdependent views of their self as part of a larger social network, people are more likely to experience other-focused emotions (Markus and Kitayama, 1991). More specifically, the Chinese culture is rooted in Confucianism which emphasizes, among others, a benign social structure based on harmony (Ip, 2009). Thus, the aim toward common good and the 
greater benefit for the many may prevail (Hofstede, 1980). Consequently, negative framing may work since the effect of the context is less strongly related to personal ego and attitudes, and thus the dampening effect of negative framing may be reduced. In fact, several reports emphasized that the ban on plastic bags was a success in China (Upton, 2013; Worldwatch Institute, 2013).

Also, companies should enforce transparent governance of their recycling practices providing the public with evidence of their recycling programs. These actions contribute to create a context in which the reuse of containers is positively valued, which could increase consumers' motivation in turn. Such a strategy would be most efficient for consumers with an Asian cultural background since context influence on motives translates into subsequent intentions and action, for Asians only, not for Westerners.

\section{Limitations and future research}

A potential limitation of his study is that while we were able to explain a considerable share of the variance of intentions, the share of variance explained in the behavior remains relatively low as observed in most studies using the TPB framework. Future research is needed to explore the extent to which intention-behavior relationship is moderated and/or mediated by other variables, and how such effects vary across cultures.

A second limitation concerns the methodology followed to test the hypotheses. We used a cross-sectional approach with selfreported data, which lacks causality. We assess prior behavior and lack therefore the longitudinal approach to predict future behavior

A third limitation is related to the issue of social desirability and memory. Our reliance on self-reports may hint to the possibility that respondents over-estimated their reusable container consumption, as an attempt to give a good image of them or possibly because they do not fully remember their reusable container consumption. One positive aspect in this regard is that we narrowed the scope of pro-environmental behavior by asking questions about very specific behaviors which may mitigate memory-related issues. Yet, whether this approach mitigates social desirability is less straightforward.

Finally, this study employed a multigroup analysis on two cultural groups, namely Asians and Westerners although this categorization may be too broad. In fact, Asians encompassed Chinese and Korean consumers mainly, whereas Westerners included Canadians and Americans. Yet, there may be some differences among Westerners and Asians themselves.

\section{Appendix A. Measurement items for principal constructs}

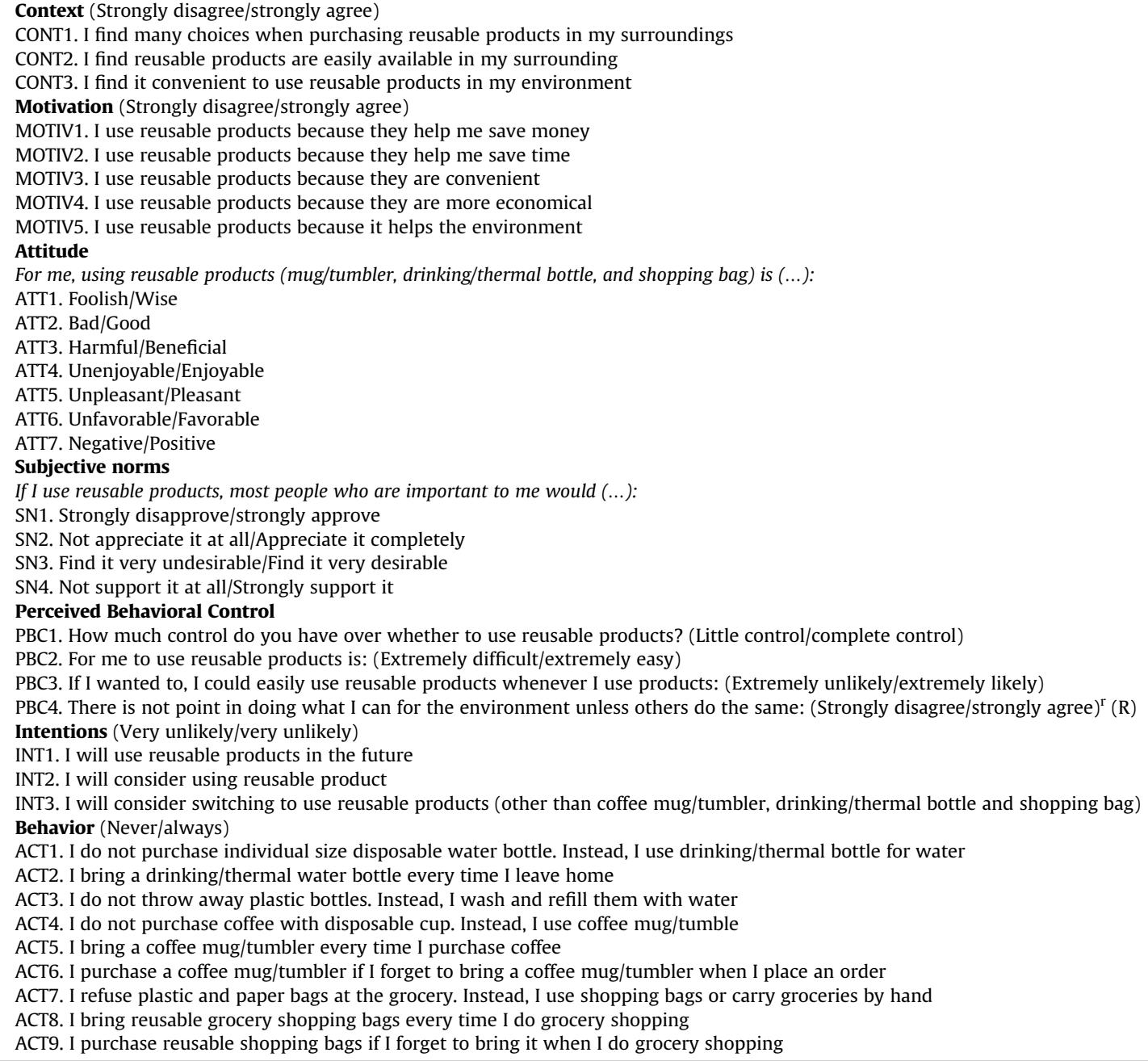




\section{References}

Accorsi, R., Cascini, A., Cholette, S., Manzini, R., Mora, C., 2014. Economic and environmental assessment of reusable plastic containers: a food catering supply chain case study. Int. J. Prod. Econ. 152, 88-101.

Adler, N.J., 2008. Global business as an agent of world benefit: new internationa business perspectives leading to positive change. In: Scherer, A.G., Palazzo, G. (Eds.), Handbook of Research on Global Corporate Citizenship. Edward Elgar Pub, Cheltenham, pp. 374-402.

Ajzen, I., 1991. The theory of planned behavior. Organ. Behav. Hum. Decis. Process. 50 (2), 179-211.

Ajzen, I., 2002. Constructing a TPB Questionnaire: Conceptual and Methodological Considerations. http://chuang.epage.au.edu.tw/ezfiles/168/1168/attach/20/pta_ 41176_7688352_57138.pdf (accessed 11 April 2016).

Ajzen, I., Fishbein, M., 1980. Understanding Attitudes and Predicting Social Behaviour. Prentice Hall, Englewood Cliffs.

Allegrini, E., Vadenbo, C., Boldrin, A., Astrup, T.F., 2015. Life cycle assessment of resource recovery from municipal waste incineration bottom ash. J. Environ. Manag. 151, 132-143.

Anderson, J.C., Gerbing, D.W., 1988. Structural equation modeling in practice: a review and recommended two-step approach. Psychol. Bull. 103 (3), 411.

Bagozzi, R.P., Warshaw, P.R., 1990. Trying to consume. J. Consumer Res. 7 (2), $127-140$.

Bagozzi, R.P., Yi, Y., 1988. On the evaluation of structural equation models. J. Acad. Mark. Sci. 16 (1), 74-94.

Bamberg, S., Möser, G., 2007. Twenty years after Hines, Hungerford, and Tomera: a new meta-analysis of psycho-social determinants of pro-environmental behaviour. J. Environ. Psychol. 27 (1), 14-25.

Botsman, R., Rogers, R., 2010. What's Mine Is Yours: the Rise of Collaborative Consumption. Penguin Press, New York.

Campbell-Arvai, V., Arvai, J., Kalof, L., 2014. Motivating sustainable food choices: the role of nudges, value orientation, and information provision. Environ. Behav. 46 (4), 453-475.

Chan, K., 1998. Mass communication and pro-environmental behaviour: waste recycling in Hong Kong. J. Environ. Manag. 52 (4), 317-325.

Corraliza, J.A., Berenguer, J., 2000. Environmental values, beliefs, and actions situational approach. Environ. Behav. 32 (6), 832-848.

Davis, G., Phillips, P.S., Read, A.D., Iida, Y., 2006. Demonstrating the need for the development of internal research capacity: understanding recycling participation using the Theory of Planned Behaviour in West Oxfordshire, UK. Resour. Conserv. Recycl. 46 (2), 115-127.

De Groot, J., Steg, L., 2007. General beliefs and the theory of planned behavior: the role of environmental concerns in the TPB. J. Appl. Soc. Psychol. 37 (8), 1817-1836.

De Leeuw, A., Valois, P., Ajzen, I., Schmidt, P., 2015. Using the theory of planned behavior to identify key beliefs underlying pro-environmental behavior in high-school students: implications for educational interventions. J. Environ. Psychol. 42, 128-138.

Denegri-Knott, J., Zwick, D., 2012. Tracking prosumption work on eBay reproduction of desire and the challenge of slow re-McDonaldization. Am. Behav. Sci. 56 (4) $439-458$.

Earth911, 2014. Paper Cups. http://earth911.com/recycling-guide/how-to-recyclepaper-cups/ (accessed 11 April 2016).

Ertz, M., Sarigöllü, E., Karakas, F., 2016. Exploring pro-environmental behaviors of consumers: an analysis of contextual factors, attitude, and behaviors. J. Bus. Res. 69 (10), 3971-3980

Feng, W., Reisner, A., 2011. Factors influencing private and public environmental protection behaviors: results from a survey of residents in Shaanxi, China. J. Environ. Manag. 92 (3), 429-436.

Fielding, K.S., Spinks, A., Russell, S., McCrea, R., Stewart, R., Gardner, J., 2013. An experimental test of voluntary strategies to promote urban water demand management. J. Environ. Manag. 114, 343-351.

Finch, D., Deephouse, D., Varella, P., 2015. Examining an individual's legitimacy judgment using the value-attitude system: the role of environmental and economic values and source credibility. J. Bus. Ethics 127 (2), 265-281.

Fornell, C., Larcker, D.F., 1981. Evaluating structural equation models with unobservable variables and measurement error. J. Mark. Res. 18 (1), 39-50.

Frazer, J.G., 1959 [1890]. The Golden Bough: a Study in Magic and Religion. Macmillan, New York.

Gifford, R., 2014. Environmental psychology matters. Psychology 65 (1), 541-579.

Grano, C., Lucidi, F., Zelli, A., Violani, C., 2008. Motives and determinants of volunteering in older adults: an integrated model. Int. J. Aging Hum. Dev. 67 (4), $305-326$.

Guagnano, G.A., Stern, P.C., Dietz, T., 1995. Influences on attitude-behavior relationships a natural experiment with curbside recycling. Environ. Behav. 27 (5), 699-718.

Haws, K.L., Winterich, K.P., Reczek, R.W., 2013. Seeing the world through GREENtinted glasses: green consumption values and responses to environmentally friendly products. J. Consumer Psychol. 24 (3), 336-354.

Hofstede, G., 1980. Motivation, leadership, and organization: do American theories apply abroad? Organ. Dyn. 9 (1), 42-63.

Hofstede, G., 1999. Problems remain, but theories will change: the universal and the specific in 21st-century global management. Organ. Dyn. 28 (1), 34-44.

Inglezakis, V.J., Moustakas, K., 2013. Household hazardous waste management: review. J. Environ. Manag. 150, 310-321.

Ip, P.K., 2009. Is confucianism good for business ethics in China? J. Bus. Ethics 88 (3), 463-476.

Ipsos InnoQuest, 2013. Global Consumers Willing to Fork Out More for Fresh and Sustainable Packaging. http://www.ipsos.com/innoquest/sites/www.ipsos.com. innoquest/files/pdf/Ipsos_InnoSpark_Packaging.pdf (accessed 04 April 2016).

Jaworski, B.J., 1988. Toward a theory of marketing control: environmental context, control types, and consequences. J. Mark. 52 (3), 23-39.

Johnson, E., 2015. Tim Hortons, Starbucks Knew Paper Cups Were Not Recycled, Employees Say. CBCnews, 6 November 2015. http://www.cbc.ca/news/business/ tim-hortons-starbucks-recycling-garbage-1.3304770 (accessed 11 April 2016).

Kenny, D.A., 2012. Measuring Model Fit. http://davidakenny.net/cm/fit.htm (accessed 11 April 2016)

Klöckner, C.A., 2013. A comprehensive model of the psychology of environmental behaviour-a meta-analysis. Glob. Environ. Change 23 (5), 1028-1038.

Koestner, R., McClelland, D.C., 1990. Perspectives on competence motivation. In: Pervin, L.A. (Ed.), Handbook of Personality: Theory and Research. Guilford Press, New York, pp. 527-548.

Kollmuss, A., Agyeman, J., 2002. Mind the Gap: why do people act environmentally and what are the barriers to pro-environmental behavior? Environ. Educ. Res. 8 (3), 239-260.

Lambert, C., 2015. Shadow Work: the Unpaid, Unseen Jobs that Fill Your Day. Counterpoint, New York.

Lamberton, C.P., Rose, R.L., 2012. When is ours better than mine? A framework for understanding and altering participation in commercial sharing systems. J. Mark. 76 (4), 109-125.

Larsen, R.J., Buss, D.M., 2008. Personality Psychology: Domains of Knowledge about Human Nature. McGraw-Hill, New York.

Lee, J.H., Kim, J.H., Hong, J.H., 2010. A comparison of adoption models for new mobile media services between high-and low-motive groups. Int. J. Mob. Commun. 8 (5), 487-506.

Leisman, K., Schmitt, M., Rohn, H., Baedeker, C., 2013. Collaborative consumption: towards a resource-saving consumption culture. Resources 2 (3), 184-203.

Liu, J., Ouyang, Z., Miao, H., 2010. Environmental attitudes of stakeholders and their perceptions regarding protected area-community conflicts: a case study in China. J. Environ. Manag. 91 (11), 2254-2262.

Markus, H.R., Kitayama, S., 1991. Culture and the self: implications for cognition, emotion, and motivation. Psychol. Rev. 98 (2), 224

Mauss, M., 1972 [1902]. A General Theory of Magic. W. W. Norton, New York.

McClelland, D.C., 1961. The Achieving Society. D. Van Nostrand, Princeton.

McClelland, D.C., 1985. How motives, skills, and values determine what people do. Am. Psychol. 40 (7), 812.

Nemeroff, C., Rozin, P., 1994. The contagion concept in adult thinking in the United States: transmission of germs and of interpersonal influence. Ethos 22 (2), 158-186.

Nordlund, A.M., Garvill, J., 2002. Value structures behind proenvironmental behavior. Environ. Behav. 34 (6), 740-756.

Numata, D., Managi, S., 2012. Demand for refilled reusable products. Environ. Econ. Policy Stud. 14 (4), 421-436.

Olli, E., Grendstad, G., Wollebaek, D., 2001. Correlates of environmental behaviors bringing back social context. Environ. Behav. 33 (2), 181-208.

Paulraj, A., 2009. Environmental motivations: a classification scheme and its impact on environmental strategies and practices. Bus. Strategy Environ. 18 (7), $453-468$.

Podsakoff, P.M., MacKenzie, S.B., Lee, J.Y., Podsakoff, N.P., 2003. Common method biases in behavioral research: a critical review of the literature and recommended remedies. J. Appl. Psychol. 88 (5), 879.

Poortinga, W., Steg, L., Vlek, C., 2004. Values, environmental concern and environmental behavior: a study into household energy use. Environ. Behav. 36 (1), 70-93.

Ramasamy, B., Yeung, M., 2009. Chinese Consumers' Perception of Corporate Social.

Ritzer, G. 2014. Automating prosumption: the decline of the prosumer and the rise of the prosuming machines. J. Consumer Cult. 15 (3), 407-424.

Ritzer, G., Jurgenson, N., 2010. Production, Consumption, Prosumption the nature of capitalism in the age of the digital 'prosumer'. J. Consumer Cult. 10 (1), 13-36.

Robbins, S.P., Judge, T.A., 2008. Organizational Behavior. Pearson Education, Upper Saddle River.

Roux, D., Korchia, M., 2006. Am I what I wear? An exploratory study of symbolic meanings associated with secondhand clothing. Adv Consumer Res. 33, 28.

Rozin, P., Markwith, M., McCauley, C., 1994. Sensitivity to indirect contacts with other persons: AIDS aversion as a composite of aversion to strangers, infection, moral taint, and misfortune. J. Abnorm. Psychol. 103 (3), 495.

Santos, G., 2008. The London experience. In: Verhoef, E., Van Wee, B., Steg, L. Bliemer, M. (Eds.), Pricing in Road Transport: a Multi-disciplinary Perspective. Edgar Elgar, Cheltenham, pp. 273-292.

Satterfield, T., Gregory, R., Klain, S., Roberts, M., Chan, K.M., 2013. Culture, intangibles and metric in environmental management. J. Environ. Manag. 117, 103-114.

Sparks, P., Shepherd, R., 1992. Self-identity and the theory of planned behavior: assessing the role of identification with "green consumerism". Soc. Psychol. Q. 55 (4), 388-399.

Steenkamp, J.B.E., Baumgartner, H., 1998. Assessing measurement invariance in cross-national consumer research. J. Consumer Res. 25 (1), 78-107.

Steg, L., Vlek, C., 2009. Encouraging pro-environmental behaviour: an integrative review and research agenda. J. Environ. Psychol. 29 (3), 309-317. 
Steg, L., Dreijerink, L., Abrahamse, W., 2005. Factors influencing the acceptability of energy policies: a test of VBN theory. J. Environ. Psychol. 25 (4), 415-425.

Stern, P.C., Dietz, T., 1994. The value basis of environmental concern. J. Soc. Issues 50 (3), 65-84.

Suthar, S., Rayal, P., Ahada, C.P., 2016. Role of different stakeholders in trading of reusable/ recyclable urban solid waste materials: a case study. Sustain. Cities Soc. 22, 104-115.

Tonglet, M., Phillips, P.S., Read, A.D., 2004. Using the Theory of Planned Behaviour to investigate the determinants of recycling behaviour: a case study from Brixworth, UK. Resour. Conserv. Recycl. 41 (3), 191-214.

Tourangeau, R., Rasinski, K.A., 1988. Cognitive processes underlying context effects in attitude measurement. Psychol. Bull. 103 (3), 299.

Triandis, H.C., 1995. Individualism \& Collectivism. Westview press, Boulder.

Tylor, E.B., 1974 [1871]. Primitive Culture: Researches into the Development of Mythology, Philosophy, Religion, Art and Custom. Gordon Press, New York.

Upton, J., 2013. China's Plastic-bag Ban Turns Five Years Old. http://grist.org/article/ chinas-plastic-bag-ban-turns-five-years-old/ (accessed 04 April 2016).

van Diepen, A., Voogd, H., 2001. Sustainability and planning: does urban form matter? Int. J. Sustain. Dev. 4 (1), 59-74.

Van Rompay, T.J.L., Tanja-Dijkstra, K., Verhoeven, J.W.M., van Es, A.F., 2012. On store design and consumer motivation: spatial control and arousal in the retail context. Environ. Behav. 44 (6), 800-820.

Vining, J., Ebreo, A., 1992. Predicting recycling behavior from global and specific environmental attitudes and changes in recycling opportunities. J. Appl. Soc.
Psychol. 22 (20), 1580-1607.

Vorkinn, M., Riese, H., 2001. Environmental concern in a local context the significance of place attachment. Environ. Behav. 33 (2), 249-263.

Wagner, T.P., Toews, P., Bouvier, R., 2013. Increasing diversion of household haz ardous wastes and materials through mandatory retail take-back. J. Environ. Manag. 123, 88-97.

Wall, R., Devine-Wright, P., Mill, G.A., 2008. Interactions between perceived behavioral control and personal-normative motives qualitative and quantitative evidence from a study of commuting-mode choice. J. Mix. Methods Res. 2 (1) 63-86.

Whitmarsh, L., O'Neill, S., 2010. Green identity, green living? The role of proenvironmental self-identity in determining consistency across diverse proenvironmental behaviors. J. Environ. Psychol. 30 (3), 305-314.

Worldwatch Institute, 2013. China Reports 66-Percent Drop in Plastic Bag Use http://www.worldwatch.org/node/6167 (accessed 11 April 2016).

Zhang, K.M., Wen, Z.G., 2008. Review and challenges of policies of environmenta protection and sustainable development in China. J. Environ. Manag 88 (4) 1249-1261.

\section{Further reading}

Fishbein, M., Ajzen, I., 2011. Predicting and changing behavior: The reasoned action approach. Taylor \& Francis. 